Гамзатова X.М. Классификация почв Дагестана в системе российской и Международной классификации почв

\title{
БИОЛОГИЯ
}

УДК 631.445.51

DOI: $10.21779 / 2542-0321-2019-34-4-126-132$

\section{Х.М. Гамзатова}

\section{Классификация почв Дагестана в системе российской и Международной классификации почв}

Дагестанский государственный университет; Россия, 367001, г. Махачкала, ул. М. Гаджиева, 43a; xalim.1980@mail.ru

В статье впервые приводится анализ почв Дагестана по трем основным классификационным системам. Автор выделил основные: Классификация почв СССР 1977 года, КиДПР и Международная классификация почв (WRB). Кроме того, в статье описаны особенности классификаций, их сходство и существенные отличия, выделены недостатки и достоинства. Автор совместно с сотрудником МГУ профессором Герасимовой М.И. приводит в статье некоторые типы почв Дагестана как пример при отнесении к той или иной классификационной группе. Сделана попытка классифицировать анализируемые почвы по различным классификационным системам, в том числе Международной. Определено классификационное положение горных почв Дагестана в системе КиДПР и WRB. Почвенный покров Дагестана отличается своим разнообразием; оно обусловлено рельефом и высотной зональностью. На равнинной части распространен каштановый тип: светло-каштановые почвы, луговые, а также пески, солонцы и солончаки. Предгорная зона характеризуется темно-каштановыми, луговыми почвами. На высоте 1500 м над уровнем моря и выше встречаются горно-лесные, бурые, степные почвы. Горный и Высокогорный Дагестан представлен горно-луговыми субальпийскими и альпийскими типами почв. Горные почвы Дагестана (почвы Дидойской депрессии) вошли в Отдел органоаккумулятивных как серогумусовая (дерновая) иллювиально-ожелезненная (маломощная). Приведённые примеры не ограничивают всего разнообразия почвенного покрова Дагестана. Данный подход позволит более детально раскрыть физико-химические свойства почв и даст современную оценку в вопросах систематики.

Ключевые слова: классификация, типы почв, ствол и отделы, эколого-генетический $и$ субстантивно-генетический принципы, реферативные почвенные группы, квалификатор.

\section{Введение}

Российская школа классификации почв, основанная на эколого-генетическом принципе, опирается на труды В.В. Докучаева и Н.М. Сибирцева. Особенностью данной классификации является учет эколого-климатических факторов. Кроме того, в ней рассматривают только целинные почвы. Эколого-генетическая классификация (1977) отличается внутренней логикой, которая отражает связь между почвой и условием почвообразования. Существенным недостатком Классификации почв 1977 г. является ее закрытость для почв, не отвечающих сложившимся представлениям о зональноподзонально-фациальных образах типов и подтипов; в ней отсутствуют почвы, используемые в сельском хозяйстве и подверженные антропогенному воздействию. Таким образом, была осознана необходимость составления новой классификации (Классификация почв России 2004 г.), которая отвечала бы современному объему знаний, построен- 
ная на субстантивно-генетическом принципе. Приближенная к Международной классификации почв, она позволяет учесть в единой классификационной структуре как природные, так и антропогенно-преобразованные почвы. Однако центральной таксономической единицей, как и в Классификации 1977 г., является тип (табл. 1). Также вводятся новые надтиповые категории - ствол и отдел. Выделяют 8 таксономических категорий, высшей из которых является ствол [1] .

Международная классификация (WRB) основана на почвенных характеристиках, содержащихся в определениях диагностических горизонтов, диагностических свойств и диагностических материалов. При выборе диагностических характеристик учитываются их связи с почвообразовательными процессами. В целом приоритетными считаются диагностические признаки, важные для использования почв. Климатические показатели не используются в WRB. Они могут быть полезны для интерпретаций в сочетании с почвенными свойствами, но их включение в определения почв не допускается. Благодаря этому классификация не зависит от доступности климатических данных, а названия почв сохраняют смысл, несмотря на глобальные или локальные изменения климата. WRB является интегральной классификационной системой, в которую могут встраиваться национальные системы классификации почв, она не предназначена для замены национальных систем классификации почв, а скорее является общим знаменателем и связующим звеном для международного общения. WRB включает два классификационных уровня: первый содержит 32 реферативные почвенные группы (РПГ); второй название каждой конкретной РПГ в сочетании с набором главных и дополнительных квалификаторов.

Классификация почв Дагестана имеет сравнительно давнюю историю развития, которая отражает все этапы накопления знаний о почвах, их свойствах и условиях их формирования. Первые сведения о классификации почв республики приведены в работах С.В. Зонна (1940), в которых приведена характеристика почв, осуществленная по высшим таксономическим единицам (типам и подтипам). Выделение их основано на всей сумме свойств почв, рассматриваемых как единое целое, развивающееся во времени и пространстве. Данный подход положен в основу систематик и номенклатуры почв, являющихся по содержанию генетическими. Данная классификация принята как основная классификационная система при картографировании почв, проведении государственного учета земель и определении общего потенциала почвенных ресурсов. Важной особенностью применяемой классификации является характеристика показателей, выявляющая природные и природно-антропогенные факторы со всеми ее свойствами, режимами, процессами. В качестве отличительного признака выступает появление новых генетически сформированных и несформированных горизонтов (слоев). Сформированные горизонты расположены параллельно с поверхностью земли, несформированные - наклонными линиями под углом разной величины $[2,3]$.

\section{Материал и методика}

Объектом классификации явились некоторые почвы Дагестана, расположенные на различных высотных отметках, а также почвы горных террас, созданные и преобразованные человеком. Предлагаемый вариант классификации почв составлен на основании существующих современных систем классификации: Классификации 1977 г., Классификации 2004 г. и Международной классификации (WRB). 
Гамзатова X.М. Классификация почв Дагестана в системе российской и Международной классификации почв

\section{Результаты и обсуждение}

Краткая отличительная характеристика существующих классификаций приведена в табл. 1, которая отражает особенности анализируемых систем. Данные системы классификаций разработаны выдающимися почвоведами - авторами, которые дополнили прежние версии, внесли огромный вклад в развитие систематики почв. Принцип построения систем классификаций - субстантивно-генетический [4-10].

Попытка классифицировать почвы Дагестана по трем основным системам классификации приведена в табл. 2. В приведенном списке почв Дагестана выделены наиболее распространённые на территории республики. При соотнесении почвы к тем или иным типам учтены их основные морфологические и физико-химические свойства.

Таблица 1. Характеристика и особенности классификационных систем

\begin{tabular}{|c|c|c|c|}
\hline $\begin{array}{c}\text { Системы } \\
\text { классификации }\end{array}$ & $\begin{array}{c}\text { Классификация } \\
1977\end{array}$ & Классификация 2004 & $\begin{array}{c}\text { Международная } \\
\text { (WRB) } 2014\end{array}$ \\
\hline Авторы & $\begin{array}{l}\text { В.В. Егоров, } \\
\text { В.М. Фридланд, } \\
\text { Е.Н. Иванова, } \\
\text { Н.Н. Розов, } \\
\text { В.А. Носин, } \\
\text { Т.А. Фриев }\end{array}$ & $\begin{array}{l}\text { Л.Л. Шишов, } \\
\text { В.Д. Тонконогов, } \\
\text { И.И. Лебедева, } \\
\text { М.И. Герасимова }\end{array}$ & $\begin{array}{l}\text { Рабочая группа WRB } \\
\text { Международного об- } \\
\text { щества наук о почве }\end{array}$ \\
\hline $\begin{array}{l}\text { Принцип по- } \\
\text { строения }\end{array}$ & $\begin{array}{l}\text { Эколого- } \\
\text { генетический }\end{array}$ & $\begin{array}{l}\text { Субстантивно- } \\
\text { генетический }\end{array}$ & $\begin{array}{l}\text { Субстантивно- } \\
\text { генетический }\end{array}$ \\
\hline Особенности & $\begin{array}{l}\text { Рассмотрены } \\
\text { только пахот- } \\
\text { но-пригодные } \\
\text { почвы; учиты- } \\
\text { ваются эколо- } \\
\text { го-климатичес- } \\
\text { кие факторы }\end{array}$ & $\begin{array}{l}\text { Рассмотрены почвы } \\
\text { всех регионов России, } \\
\text { учтены антропоген- } \\
\text { ные изменения почв; } \\
\text { приближена к Меж- } \\
\text { дународной системе } \\
\text { (WRB) }\end{array}$ & $\begin{array}{l}\text { Открытость и унифи- } \\
\text { цированность системы }\end{array}$ \\
\hline $\begin{array}{l}\text { Таксономиче- } \\
\text { ский список } \\
\text { (структура) }\end{array}$ & 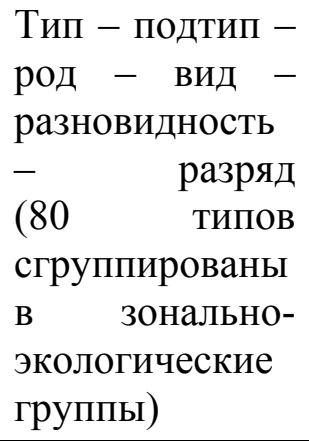 & $\begin{array}{l}\text { Ствол - отдел - тип - } \\
\text { подтип - род - вид - } \\
\text { разновидность - раз- } \\
\text { ряд (стволы - постли- } \\
\text { тогенные, органоген- } \\
\text { ные, синлитогенные). } \\
\text { Таксономическая еди- } \\
\text { ница: тип }\end{array}$ & $\begin{array}{l}\text { Два таксономических } \\
\text { уровня: } \\
\text { Реферативные почвен- } \\
\text { ные группы (РПГ); } \\
\text { РПГ с набором квали- } \\
\text { фикаторов - главных и } \\
\text { дополнительных, чис- } \\
\text { ло которых не ограни- } \\
\text { чено }\end{array}$ \\
\hline
\end{tabular}

Ocобое значение классификации и систематики для почвенного покрова Дагестана заключается в том, что значительная часть горной зоны слабо изучена (рис. 1). Важным объектом классификации явились почвы горных террас, созданные и преобразованные человеком. Использование горных земель осуществляется на склонах с крутизной $25-30^{\circ}$, расположенных по склонам долин рек. В горной зоне в распашку вовлекаются горно-долинные террасы и межтеррасные откосы, площади их образуются соору-

128 Вестник Дагестанского государственного университета

Серия 1. Естественные науки. 2019. Том 34. Вып. 4 
жением каменных стен, это сопровождается формированием антропогенных почв, представляющих новый объект классификации.
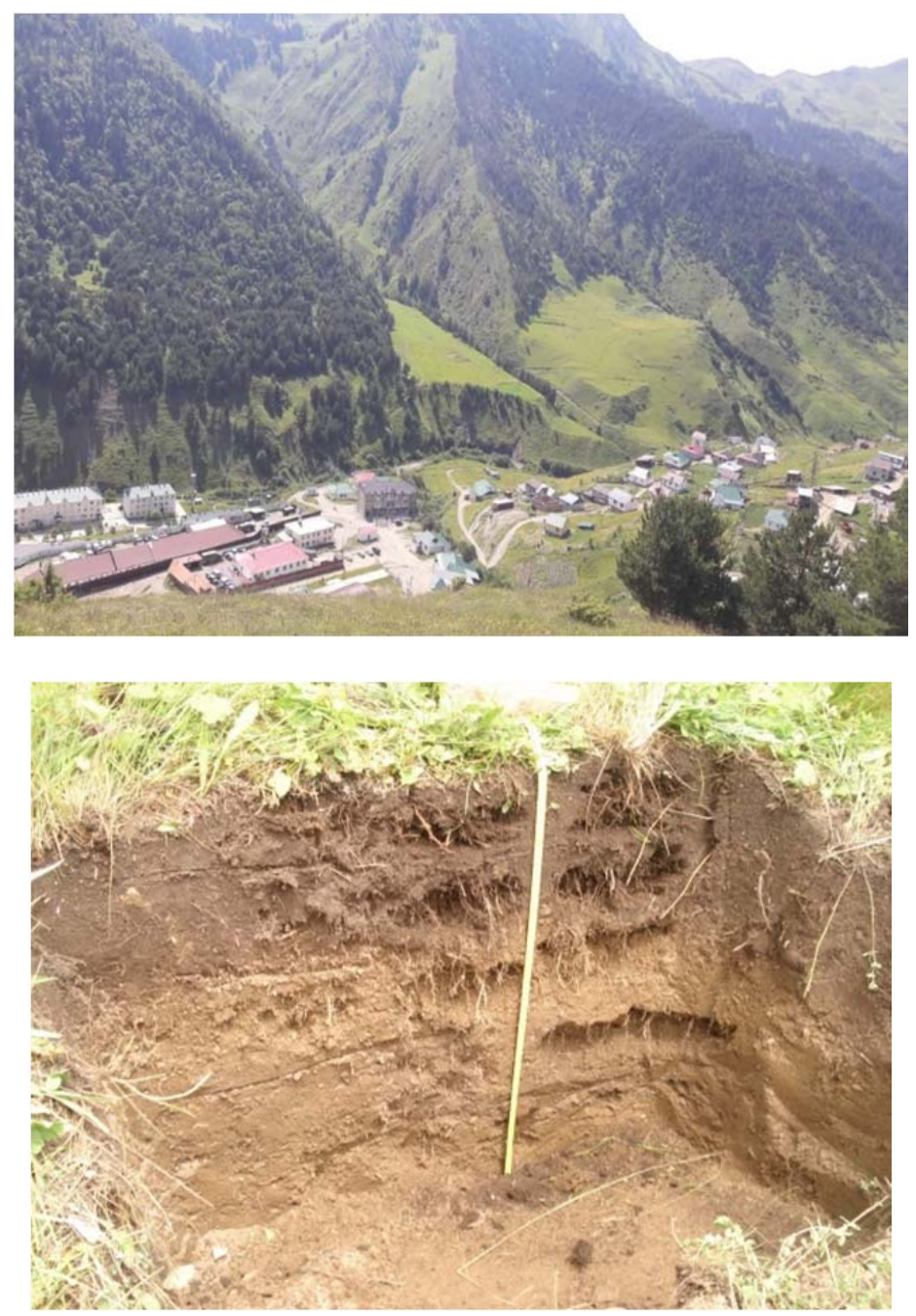

Рис. 1. Высокогорный Дагестан

Горные террасные почвы в основном имеют антропогенное происхождение, и возникает необходимость определить их место в общей классификационной системе. Использование горных почв в настоящее время находится в неконтролируемом состоянии, где наблюдается разрушение террас и почвенного покрова.

Горно-луговые и горно-лесные почвы (Leptic Phaeozems) по новой классификации (2004) не представлены самостоятельным типом (табл. 2), они вошли в Отдел аккумулятивно-гумусовых, где среднее количество гумуса составило 7-8 \%, в субальпийских почвах - 12 \% [3], ЕКО равна 35-40 мг-экв/100 г. 
Гамзатова X.М. Классификация почв Дагестана в системе российской и Международной классификации почв

Таблица 2. Систематический список почв Дагестана по различным классификациям

\begin{tabular}{|c|c|c|c|}
\hline № & $\begin{array}{l}\text { Классификация почв } \\
1977\end{array}$ & Классификация почв 2004 & $\begin{array}{l}\text { Международная } \\
\text { (WRB) } 2014\end{array}$ \\
\hline 1 & $\begin{array}{l}\text { Каштановые } \\
\mathrm{A}_{1} \mathrm{~A}_{2}-\mathrm{B}-\mathrm{C}_{1} \mathrm{C}_{2} \mathrm{C}_{3}\end{array}$ & $\begin{array}{l}\text { Ствол: постлитогенные } \\
\text { Отдел: аккумулятивно-карбонатные } \\
\text { малогумусовые почвы; } \\
\text { каштановые } \\
\text { AJ-BMК-CAT-Cca }\end{array}$ & Kastanozems \\
\hline 2 & $\begin{array}{l}\text { Лугово-каштановые } \\
\text { A-B- } \mathrm{C}_{1} \mathrm{C}_{2} \mathrm{C}_{3}\end{array}$ & $\begin{array}{l}\text { Отдел: аккумулятивно-карбонатные } \\
\text { малогумусовые почвы; } \\
\text { каштановые гидрометаморфизованные } \\
\text { AJ-BMK-CATq-Q }\end{array}$ & $\begin{array}{l}\text { Gleyic } \\
\text { Kastanozems }\end{array}$ \\
\hline 3 & $\begin{array}{l}\text { Луговые } \\
\text { A-B-BC-C } 1-C_{2}\end{array}$ & $\begin{array}{l}\text { Отдел: глеевые почвы; } \\
\text { темногумусово-глеевые } \\
\text { AU-G-CG }\end{array}$ & $\begin{array}{l}\text { Gleyic } \\
\text { Phaeozems }\end{array}$ \\
\hline 4 & $\begin{array}{l}\text { Лугово-болотные } \\
\mathrm{A}_{0}-\mathrm{A}_{1}-\mathrm{B}-\mathrm{B}_{1}\end{array}$ & $\begin{array}{l}\text { Отдел: глеевые почвы; } \\
\text { перегнойно-глеевые } \\
\text { H-G-CG(ca) }\end{array}$ & $\begin{array}{l}\text { Reductic Mollic } \\
\text { Gleysols }\end{array}$ \\
\hline 5 & $\begin{array}{l}\text { Солончаки } \\
\mathrm{A}-\mathrm{B}-\mathrm{B}_{1}-\mathrm{C}_{1}-\mathrm{C}_{2}\end{array}$ & $\begin{array}{l}\text { Отдел: галоморфные почвы; } \\
\text { S-Cs,cs,q }\end{array}$ & Solonchaks \\
\hline 6 & $\begin{array}{l}\text { Солонцы, солончаки } \\
\mathrm{A}-\mathrm{B}-\mathrm{B}_{1} \mathrm{C}-\mathrm{C}_{1}-\mathrm{C}_{2}\end{array}$ & $\begin{array}{l}\text { Отдел: } \quad \text { щелочно-глинисто- } \\
\text { дифференцированные почвы; } \\
\text { солонцы солончаковые } \\
\text { SEL-BSN-BCAs,cs-Cca,s }\end{array}$ & Salic Solonetz \\
\hline 7 & $\begin{array}{l}\text { Коричневые почвы } \\
\text { сухих лесов и ку- } \\
\text { старников }\end{array}$ & $\begin{array}{l}\text { Отдел: структурно-метаморфические } \\
\text { почвы; } \\
\text { Коричневые } \\
\text { AU-BM-BCA-Cca }\end{array}$ & $\begin{array}{l}\text { Eutric Chromic } \\
\text { Cambisols }\end{array}$ \\
\hline 8 & $\begin{array}{l}\text { Бурые лесные } \\
\text { A }_{0}-A_{1}-A B-B C-C_{1}\end{array}$ & $\begin{array}{l}\text { Отдел: структурно-метаморфические } \\
\text { почвы; } \\
\text { бурозёмы } \\
\text { Y-ВМ-C }\end{array}$ & Cambisols \\
\hline 9 & $\begin{array}{l}\text { Горные черноземы } \\
\text { A-B-BC-C } 1\end{array}$ & $\begin{array}{l}\text { Отдел: органо-аккумулятивные почвы; } \\
\text { тёмногумусовые } \\
\text { AU-C }\end{array}$ & Mollic Leptosols \\
\hline 10 & $\begin{array}{l}\text { Горные лугово-лес- } \\
\text { ные } \mathrm{A}_{0}-\mathrm{A}_{1}-\mathrm{A}_{2}-\mathrm{B}-\mathrm{C}\end{array}$ & $\begin{array}{l}\text { Отдел: органо-аккумулятивные почвы; } \\
\text { серогумусовые (дерновые) } \\
\text { AY-C }\end{array}$ & Leptic Phaeozems \\
\hline 11 & Пески & $\begin{array}{l}\text { Отдел: слаборазвитые почвы; } \\
\text { псаммоземы } \\
\text { W-C }\end{array}$ & Arenosols \\
\hline
\end{tabular}

\section{Заключение}

Приведенные примеры отнесения дагестанских почв к различным системам классификации не исчерпывают их разнообразия. В статье трудно представить полную ин- 
формацию о современных системах классификации с определением положения в них почв Дагестана. Объект почвоведения многогранен; при необходимости сведения по классификации почв можно найти в книге «Классификация и диагностика почв России» [11-13], а также на сайте: https://soil-db.ru/; http://soils.narod.ru/; http://infosoil.ru/reestr/;http://infosoil.ru/.

Исходя из вышеизложенного, приведённый систематический список типов почв Дагестана необходимо учитывать для предметного суждения о результатах полученных исследований и обсуждения их доказательности.

\section{Литература}

1. Шишов Л.Л., Тонконогов В.Д., Лебедева И.И., Герасимова М.И. Классификация и диагностика почв России. - Смоленск: Ойкумена, 2004. - 342 с.

2. Залибеков 3.Г. Почвы Дагестана. - М., 2010. - 243 с.

3. Гамзатова X.M. Биологические особенности разнообразия почв Дидойской депрессии Горного Дагестана: автореф. дис. ... к. биол. н. - Махачкала: Издательство ДГУ, 2018.

4. Герасимова М.И. Сравнение принципов, структуры и единиц классификации почв России и международной почвенной классификации // Бюллетень Почвенного института им. В.В. Докучаева. - 2015. - Вып. 79. - С. 23-35.

5. Лебедева И.И. Тонконогов В.Д., Герасимова М.И. Новая классификация почв России: предварительные итоги обсуждения // Почвоведение. - 2008. - № 1. - С. 102-109.

6. Рожков В.А. Классиология и классификация почв // Почвоведение. - 2012. № 3. - C. 259-269.

7. Федоров А.С., Суханов П.А., Касаткина Г.А. Федорова Н.Н. О новой классификации почв России // Вестник СПбГУ. Сер. 7. - 2004. - Вып. 1. - С. 95-112.

8. Залибеков 3.Г., Бирасланов А.Б., Залибекова М.З., Сулейманова П.М.-С. Содержание гумусовых веществ и их значение для разработки теории // Вестник ДГУ. Cер. 1: Естественные науки. - 2013. - Вып. 6. - С. 126-131.

9. Рожков В.A. Концепция генератора (машины) классификаций почв // Бюллетень Почвенного института им. В.В. Докучаева. - 2016. - Вып. 85. - С. 115-130.

10. Рожков B.A., Симакова М.C. Многомерная статистика в анализе данных о морфологии почв // Материалы Всероссийской конференции с международным участием «Морфология почв: от макро- до субмикроуровня» (Москва, 19-21 декабря 2016 г.). М.: Почвенный институт им. В.В. Докучаева, 2016. - С. 271-273.

11. Единый государственный реестр почвенных ресурсов России. Версия 1.0. М.: Почв. институт им. В.В. Докучаева, 2014. - 768 с.

12. Ананко Т.В., Герасимова М.И., Конюшков Д.Е. Почвы горных территорий в Классификации почв России // Бюллетень Почвенного института им. В.В. Докучаева. 2018. - № 92. - С. 122-146.

13. Национальный атлас почв Российской Федерации / под ред. С.А. Шобы. М.: Астрель, 2011. - 631 с.

Поступила в редакичию 1 июля 2019 г. 
DOI: $10.21779 / 2542-0321-2019-34-4-126-132$

\title{
Classification of soils of Dagestan in the system of Russian and International soil classification
}

\section{H.M. Gamzatova}

\author{
Dagestan State University; Russia, 367001, Makhachkala, M. Gadzhiev st., 43a; \\ xalim.1980@mail.ru
}

The article provides first analysis of the Dagestan soils in the three main classification systems. The author has provided the main ones: classification of soils 1977, classification and diagnosis of soil resources (C\&DSR), and the international soil classification (WRB). In addition, the article describes the features of classifications, their similarities and significant differences, the highlighted disadvantages and advantages. The author together with an employee of MSU Professor Gerasimova M.I. describes some types of Dagestan soils in the article, as an example when referring to a particular classification group. An attempt is made to classify the analyzed soils according to different classification systems, including International one. The classification status of mountain soils of Dagestan in classification and diagnosis of soil resources (C\&DSR) and WRB is determined. The soil cover of Dagestan is distinguished by its diversity which is due to the relief and high-altitude zoning. On the flat part of the common chestnut type: light chestnut, meadow, sand, as well as Solontsy and Solonchaki. Foothill zone is characterized by dark chestnut, meadow soils. At an altitude of $1500 \mathrm{~m}$ above sea level and higher one can meet mountain-forest brown, steppe soil. Mountain and mountainous Dagestan are represented by mountain-meadow subalpine Alpine soil types. The mountain soils of Dagestan (Dido depression) was included in the Department of Organic-accumulative as Stroganova (sod) illuvialferruginous (low-power). These examples do not limit the diversity of the soil cover of Dagestan. This approach will allow to reveal in more detail physical and chemical properties of soils and will give a modern assessment in questions of systematics.

Keywords: classification, soil types, trunk and departments, ecological-genetic, and substantive-genetic principles, abstract soil groups, qualifier.

Received 1 July, 2019 